\title{
A Review on the use of High Density Polyethylene (HDPE) in Concrete Mixture
}

\author{
Tabish Wani, Syed Afsar Quadri Pasha, Sanskar Poddar, Balaji H V \\ Dayananda Sagar College of Engineering
}

\begin{abstract}
The rapid industrialization and urbanization in our country has resulted in significant rise in the quantity of plastic waste. Most of polymer wastes is abandoned and not recycled. It leads to serious problems of wastage of natural resources and environmental pollution. Synthetic fibers, plastics and rubber belong to petrochemical compounds and are not easily biodegradable. This problem can be reduced by using plastic waste in the production of concrete. It helps in reducing concrete cost, land-fill cost, energy saving and protection of environment from pollution.

Concrete with replacement of certain percentages of polyethylene material is prepared after mix design. Various tests on cement like specific gravity, fineness modulus, strength tests, setting time, etc. are performed. Mix design using IS Code method is done and cubes, beams and cylinders are casted with and without plastics and tests on concrete like slump test. The mechanical properties of concrete like compressive strength, split tensile and flexure test are conducted and compared with the result of standard specimen. As for cost analysis, the results showed that polymer concrete is more cost effective than conventional concrete. As part of case study A multi-storied building is taken and data is collected, building frame model is developed and is analyzed.
\end{abstract}

Key Words- Light weight concrete, Polymer waste, Mechanical properties, HDPE.

\section{INTRODUCTION}

Lightweight concrete can be defined as a type of concrete which includes an expanding agent in that it increases the volume of the mixture while giving additional qualities such as lessened dead weight. The term lightweight concrete itself describes a wide range of special aggregate bases. The specific gravities and in terms of density of compactness of these aggregates are significantly lower than that of normal weight concrete aggregates. Lightweight concrete can be used for as lighter weight thermal insulate and non-structural as well as structural

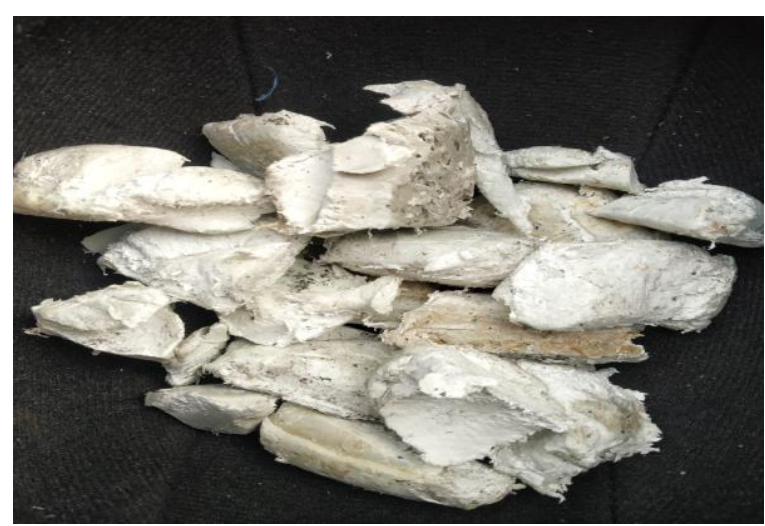

Figure 1 High Density Polyethylene (HDPE). concrete composed of extremely light natural or manmade aggregate.

Multi-storied buildings are indispensable in urban areas due to high cost of land, shortage of open space and scarcity of lands. Many times, these multi story buildings are built with regular concrete, steel and other materials where the loads are high and require heavy structures and cost may not be effective. The use of light weight concrete and lightweight materials will reduce the dead load of a structure, which then allows the structural designer to reduce the size of the columns, footings, and other load bearing elements. Structural light weight concrete mixtures can be designed to achieve similar strengths as normal weight concrete

Fine aggregate used in concrete is replaced partially by plastic wastes in known percentages and properties are tested, the optimum percentage at which higher strength is obtained is calculated. Advantages of using waste or recycled plastics are it will help on reducing the municipal solid wastes being land filled and it became an alternative to pressure-treated lumber that leaches toxic chemical into water. There are many types of waste and recycled plastic that has been used in concrete mix.

In this paper, an attempt has been made to study HDPE plastic (high-density polyethylene). HDPE has stronger material properties, harder, opaque and more resistant to high temperatures. HDPE is commonly used for colored milk bottles, oil container, shampoo bottles, and much more. HDPE is one of the safe plastic materials because of the ability to prevent chemical reactions between HDPE plastic packaging and the packaged food or beverages. HDPE is the polyethylene grade with the highest rigidity and the least amount of flexibility. It is well suited for a wide range of applications, like trash canisters, and a multitude of everyday household goods, such as small bottles and clothespins. This light-weight, non-toxic material is easily recyclable and serves increasingly as an alternative for less environmentally friendly substances.

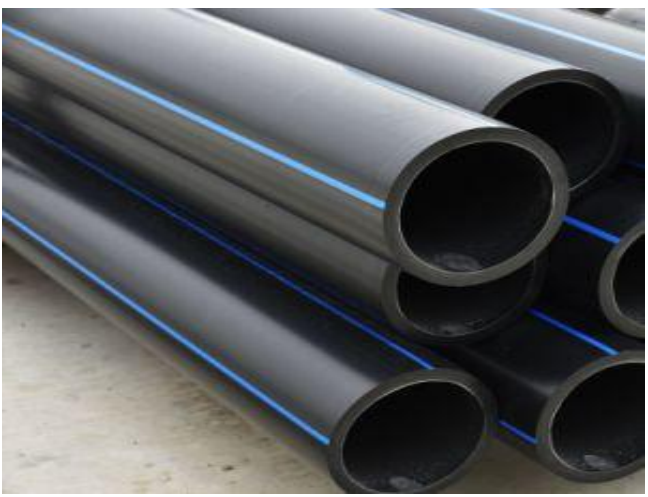

Figure 2 HDPE Pipes. Courtesy internet 
Raghatate Atul M.[1], He has done research on "Use Of Plastic In A Concrete To Improve Its Properties". Plastic bags which are commonly used for packing, carrying vegetables, meat etc. creates a serious environmental problem. Plastic bag last in environment up to 1000 years because of plastic bag last so long the number of plastic bag accumulated increases each year. Disposal of large quantity of plastic bag may cause pollution of land, water bodies and air. The proposed concrete which is made up by adding plastic in concrete may help to reuse the plastic bag as one of the constituent's material of concrete, to improve the certain properties of concrete. The properties of concrete containing varying percentages of plastic were tested for compressive strength and Split tensile strength and shows that an appreciable improvement in tensile strength of concrete can be achieved by introducing cut pieces of plastic bags.

H. Bomhard Et. Al [2] "Lightweight concrete structures potentialities, limits and realities" This paper was published as part of the Proceedings of the CI80 Congress on Lightweight Concrete, London; The International Journal of Lightweight Concrete, Volume 2, Number - 4 Dec, (1980) by concluded that Structural lightweight concrete can be economical especially in the combination of high loadbearing capacity and low density, but also by the low density alone.

Kamsiah Mohd. Ismail Et. Al. [3] "Study of Lightweight Concrete Behaviour". This research work

\begin{tabular}{|c|c|}
\hline \multicolumn{2}{|c|}{ Structural details of $\mathrm{LWC}(\mathrm{G}+15)$ building: } \\
\hline i. Number of storey & $15(G+14)$ \\
\hline ii. Height of storey & $2.8 \mathrm{~m}$ with G.F column and storey column $3.0 \mathrm{~m}$ \\
\hline iii. Cross-section of beams & $350 \times 300$ \\
\hline iv. Cross-section of columns & $\begin{array}{l}\text { as follows } 350 \times 400 \text { in Outer section, } \\
400 \times 400 \text { in intermediate section, } \\
500 \times 600 \text { in core column sand base. }\end{array}$ \\
\hline v. Span of beam & $4 \mathrm{~m}$ (x-dir) \& $4 \mathrm{~m}$ (y-dir). \\
\hline vi. Grade of concrete & M35 \\
\hline vii. Grade of steel & Fe 415 \\
\hline viii. Dead Load & -1 factor load and $-2.5 \mathrm{kN} / \mathrm{m} 2$ as floor load. \\
\hline ix. Live Load & $1.5 \mathrm{KN} / \mathrm{m} 2$ on Floor and 2 on beams. \\
\hline x. Seismic Load & As per IS: $1893-2002$, with $\mathrm{Z}=0.1$, \\
\hline
\end{tabular}

Analysis of Building: Analysis is done by using STAAD. Pro under design consideration IS: 456 - 2000 and IS: 13920 -1993. Appling the response spectrum command loading for dynamic analysis. This capability allows for analyzing the structure for seismic loading. for any supplied response spectrum (either acceleration vs. period thesis is carried (2004) and the initial findings have shown that the lightweight concrete has a desirable, strength to be an alternative construction material for the industrialized building system. The foamed lightweight concrete is not suitable to be used as non-load bearing wall as the compressive strength is $27 \%$ less than recommended. Nevertheless the compressive strength is accepted to be produced as non-load bearing structure.

Jan A. Overli Et. Al. [4] "Increasing ductility in heavily reinforced LWAC structures" in Engineering Structures Volumes 62-63, Jensen founded that the ductility index proved to be the same for beams with fiber or stirrups, and was almost doubled for beams with both fiber and stirrups and The effect of adding steel fiber reinforcement in the compressive gradient zone of full-scale, over reinforced LWAC beams was much more pronounced regarding ductility than the effect achieved from tests of stress-strain relationships on cylinders with the same fiber reinforced LWAC.

\section{Case study [5]}

The experimental setup has been done to analyze the effects of structural lightweight concrete seismic behavior in High - rise building by framing out simulation model in STAAD.Pro software tool. The building is having fifteen stories and overall $44.8 \mathrm{~m}$ assembled as $\mathrm{G}+14$. The building to be analyzed here is completely made up of lightweight concrete; structural members includes both horizontal and vertical members. or displacement vs. period), joint displacements, member forces, and support reactions may be calculated. Modal responses are combined using the complete quadratic combination (CQC), methods to obtain the resultant responses. 


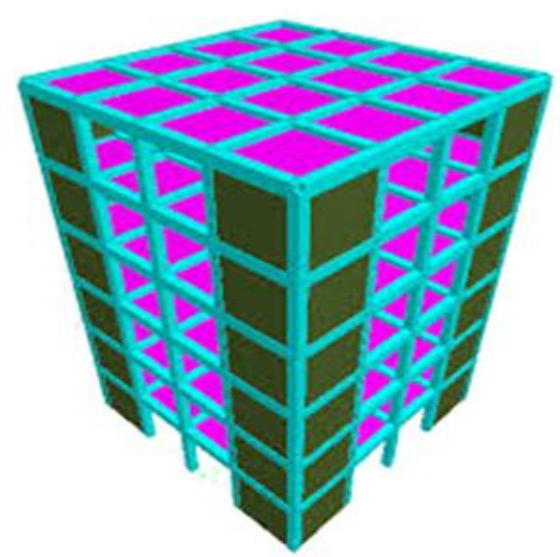

RESULT ANALYSIS

A light weight concrete structure is analyzed on the basis of codal provisions and in STAAD.pro software with different specifications of design details as specified previously. The result analysis is obtained by the software as per the feaded data.

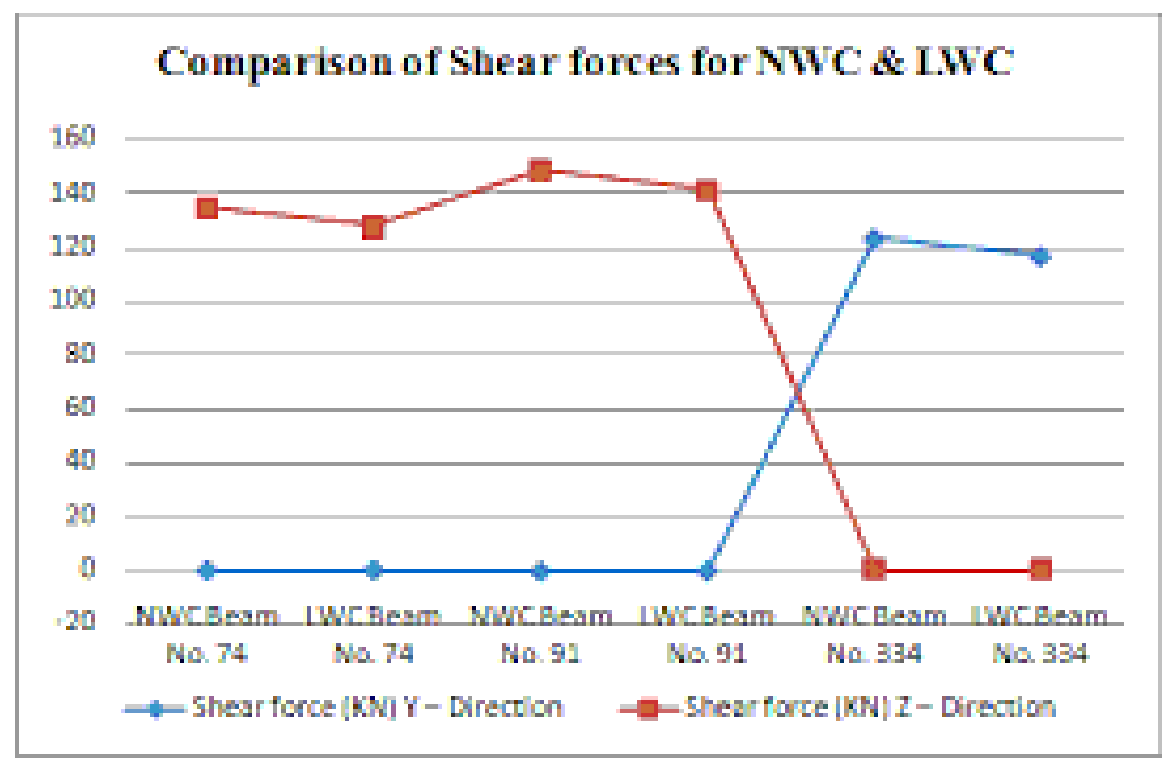

TABLE 1 Comparison Of Shear Forces.

\begin{tabular}{|c|c|c|c|c|c|}
\hline Mode & $\begin{array}{l}\text { Frequency } \\
\text { Hz }\end{array}$ & $\begin{array}{l}\text { Period } \\
\text { seconds }\end{array}$ & $\begin{array}{l}\text { Participation X } \\
\text { \% }\end{array}$ & $\begin{array}{l}\text { Participation Y } \\
\text { \% }\end{array}$ & $\begin{array}{l}\text { Participation Z } \\
\%\end{array}$ \\
\hline 1 & 0.757 & 1.320 & 78.193 & 0.000 & 0.000 \\
\hline 2 & 0.777 & $1.28 \$$ & 0.000 & 0.000 & 77.645 \\
\hline 3 & 0.854 & 1.170 & 0.000 & 0.000 & 0.000 \\
\hline 4 & 2.306 & 0.434 & 9.737 & 0.000 & 0.000 \\
\hline 5 & 2.371 & 0.422 & 0.000 & 0.000 & 9.362 \\
\hline 6 & 2.581 & 0.387 & 0.000 & 0.000 & 0.000 \\
\hline
\end{tabular}

TABLE 2 Max beam stresses under applied loads for M35 grade concrete with fe415.

Results as obtained from tabulated data and graphical representations shows that there is considerable fall down in shearing forces and moments along all coordinate axes under applied structural defined loads like; dead, live and seismic loadings. The loads causes significance vibrations, which make structure to deform or get displaced from connecting joints, or say; the node to node displacements. Data shows that the structural entity assembled is at most on critical side as if not properly investigated for seismic 
time period and its after affects (bursting of column and beams in lateral direction) which might be disastrous.

The confined detailed go-through in this research work study reveals that the Light weight concrete reduces effect of seismic vibrations and reduces threat of structural collapse under base shear, storey drift and soft storey effect. Lower density material reduces seismic vibration effect by allowing forces to pass through structural members. Amount of reinforcement required in Light weight concrete structure is lesser than Normal weight concrete as the value of moments get reduced. Danger of story drift under seismic response is reduced by increasing stiffness of members. Ductility of structure is also increased by using light weight concrete due to reduction in dense medium, which retards and dumps the seismic vibrations within it.

\section{CONCLUSIONS:}

On comparison between normal weight and light weight RCC building under similar load cases it has been observed that, Shearing, Tearing and Moments are considerably reduced in light weight concrete Structure. Light weight concrete structures in aseismic conditions save considerably on cost of the entire project. The percentage of reinforcement required is also reduced for light weight concrete members as moment acting on the member gets reduced. The dynamic analysis results so obtained shows that structure undergoes high lateral deformation and deflection but remain safe even under critical values of forces.

\section{REFERENCES:}

[1] Raghatate Atul Use of plastic in a concrete to improve its properties, E-ISSN2249-8974. Use of plastic in a concrete to improve its properties, E-ISSN2249-8974. Green concrete using plastic waste

[2] H. Bomhard (1980), "Lightweight concrete structures potentialities, limits and realities" The International Journal of Lightweight Concrete, Volume 2, No - 4 Dec, Page No. 193 196.

[3] Hjh Kamsiah Mohd. Ismail [6] "Study of Lightweight Concrete Behaviour" in his research work thesis Page No 1 - 35 (2004)

[4] Jan A. Overli "Increasing ductility in heavily reinforced LWAC structures" in Engineering Structures Volumes 62-63, pp 1-26 (2014)

[5] Chandan Nirmal, Dr S K Jaiswal " Dynamic Analysis of High Rise Building Structure with Lightweight concrete" in his research page $368-372$

[6] G. Li, M.A. Stubblefield, G.Garrick, J.Eggers, C. Abadie, B. Huang. Development of Waste Tire Modified Concrete. Cem Concr Res 34 (2004) 2283-2289

[7] Safan, Agarwal, Solid Wate Recycling, Malaysian Perspective. Frost and Sulivan Market Insight (2007).

[8] Harper, Charles A., Edward M. Petrie, Plastics Materials and Processes, John Wiley \& Sons. (2003). 